\title{
Determination of Stability Constants of Iron(II) Complexes of as-Triazines Containing Ferroin-Yielding Chromogens
}

\author{
Md. Anwarul Islam, ${ }^{1}$ Shahida Begum, ${ }^{1}$ Maksuda Parvin ${ }^{1}$ and Md. Musharraf Hossain ${ }^{2}$ \\ ${ }^{1}$ Department of Chemistry, Dhaka University, Dhaka-1000, Bangladesh \\ ${ }^{2}$ Department of Chemistry, Jashore University of Science and Technology, Jashore 7408, Bangladesh
}

(Received : 16 January 2020; Accepted : 4 October 2020)

\begin{abstract}
With the aim of determining stability constants of iron(II) complexes of 3-(2-pyridyl)-5,6-diphenyl-1,2,4-triazine (PDT), 3-(2pyridyl)-5,6-bis(p-methoxyphenyl)-1,2,4-triazine (PBMPT) and 3-(2-pyridyl)-5,6-bis(4-biphenyl)-1,2,4-triazine (PBBT), these organic reagents were prepared from commercially available relatively cheaper reactants. The absorptiometric characteristics of iron(II) complexes of these organic compounds; $\lambda_{\max }$ and molar absorptivity $\left(\epsilon_{\max }\right)$ were determined. The composition and stability constants of these iron(II) complexes were determined by both molar ratio and Job's continuous variation methods. The mean $\operatorname{logK}$ values for iron(II) complexes of PDT, PBMPT and PBBT were found 16.48, 17.48 and 15.54 respectively reflecting the formation of very stable complexes. These are well comparable with the reported values for the iron(II) complexes of 2,2'-bipyridine, 1,10- phenanthroline, Ferrozine and Ferene. Higher sensitivity and stability constant values reflects the possibility of application of these compounds as promising chromogenic reagents for iron determination.
\end{abstract}

Keywords: Spectrophometric reagents, UV-visible Spectrophotometer, stability constant.

\section{Introduction}

Organic reagents play significant roles in determination of different metal ions spectrophotometrically because of their superiority over inorganic reagents which include sensitivity and selectivity. These reagents find many applications in the analytical chemistry of many inorganic species $^{1,2}$. The stability constant values of metal complexes are required for their application in different situations with high reliability. Examples of consideration of the stability constant values of complexes are the fields of meal extraction, nuclear energy industry, environmental, and industrial research etc ${ }^{3}$. Application of coordination compounds in medical science e.g. gadolinium-DTPA complex in MRI contrast enhancement requires stability constant data. The large stability constant value of this complex ensures the negligible concentration of free $\mathrm{Gd}^{3+}$ since it is very toxic. In designing metal ion buffers for use in biological systems and standardizing ion-selective electrodes stability constant data is required ${ }^{4}$.

The organic compounds containing ferroin functional group ${ }^{5}$ are widely used for the trace level determination of iron(II). 1,10-Phenanthroline is one of the well-known example and widely used for the determination of iron (II) $\left(\varepsilon=11,000 \mathrm{dm}^{3} \mathrm{~mol}^{-1} \mathrm{~cm}^{-1}\right.$ at $\left.510 \mathrm{~nm}\right)$. The reported value of the stability constant $(\log K)$ for iron(II) complex of 1,10 Phenanthroline is 20.2-21.5 ${ }^{6,7}$.

Case and his co-workers ${ }^{8-11}$ have reported the preparation of some as-triazines containing ferroin functional group. Schilt $^{12}$ has evaluated them as spectrophotometric reagents. Of these as-triazines, 3-(2-py)-5,6-diphenyl-as-triazine (PDT) has gained a great deal of popularity as a chromogenic reagent for the determination of iron despite the fact that its iron(II) chelate has comparatively lower molar absorptivity of 24000 at $555 \mathrm{~nm}^{13}$ compared to PPDT [3-(4-phenyl-2-py)-5,6-diphenyl-as-triazine]. However, the stability constant of its (PDT) complex with iron (II) has not been reported yet.

A sulphonated derivative of PDT has been reported by Stookey $^{14}$ which is readily soluble in water. Since its introduction in 1970, 3-(2-py)-5,6-bis(4-phenylsulphonic acid)-as-triazine, monosodium salt, monohydrate assigned the trival name, Ferrozine, is being widely for iron determination. Gibbs $^{15}$ has reported the details of synthesis of ferrozine, its purification and conditional formation constant of its iron(II) complex. Smith et al. have reported the synthesis of a very sensitive ferroin-yielding chromogen; 3-(2-py)-5,6-bis[2-(5furylsulphonic acid)]-as-triazine disodium salt, dihydrate, assigned the trivial name, Ferene and the spectral characteristics of its iron(II) chelate. Ferene forms a trischelate with iron(II) in aqueous medium having absorptivity of $34,500 \mathrm{dm}^{3} \mathrm{~mol}^{-1} \mathrm{~cm}^{-1}$ at $593 \mathrm{~nm}$. The reported value of the stability constant (logK) for Ferene-iron(II) complex is $14.9^{16}$.

Searching for superior chromogenic reagents, Stephen and Islam ${ }^{17}$ have reported fourteen new as-triazines incorporating various appropriate substituents at 3-, 5- and 6- positions along with the chromophoric enhancement of the ferroin functional group due to different substituents at 5- and 6positions of as-triazines. Recently three among the fourteen as-triazines have been successfully utilized for the determination of $\mathrm{Fe}(\mathrm{II})$ in different water samples spectrophotometrically ${ }^{18}$. However, the stability constants of iron(II) complexes of these as-triazines have not been reported by Stephen and Islam. Literature survey so far revealed that there is no report on the stability constant of iron(II) complexes of those as-triazines. Thus, there appears the scope of finding the stability constants of iron(II) complexes of these new promising spectrophotometric reagents. In this study, the conditional formation constants (stability constants) of iron(II) complexes of some astriazines have been determined along with their composition and other spectrophotometric characteristics.

*Author for correspondence. e-mail: manwaruli@yahoo.com 


\section{Experimental}

Preparation of 3,5,6-trisubstituated as-triazines

Three as-triazines; 3-(2-pyridyl)-5,6-diphenyl-1,2,4-triazine (PDT), 3-(2-pyridyl)-5,6-bis(p-methoxyphenyl)-1,2,4-triazine (PBMPT) and 3-(2-pyridyl)-5,6-bis(4-biphenyl)-1,2,4-triazine (PBBT) were prepared from commercially available relatively cheaper reagents following methods described in Vogel's text book of practical organic chemistry ${ }^{19}$ and of Stephen and Islam $^{17}$ according to the following the reaction scheme.
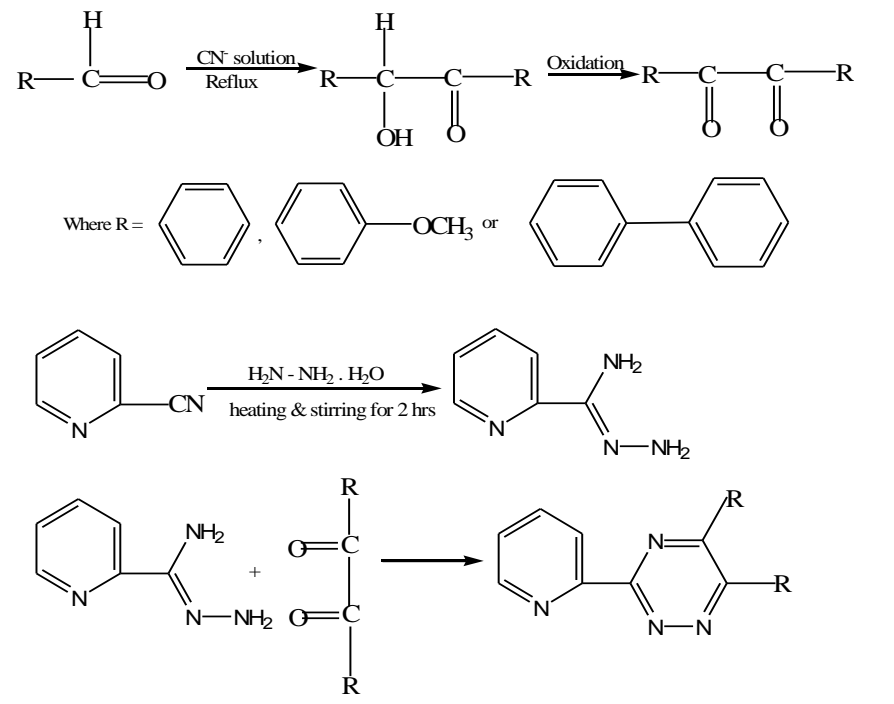

Schematic diagram for synthesis of as-triazines.

Spectrophotometric examination of reaction of as-triazines with iron(II)

Reagents

\section{Stock iron(II) solution}

A standard stock iron(II) solution was prepared by dissolving $3.51 \mathrm{~g}$ of analaR grade Mohr's salt in small volume of distilled water and $5-\mathrm{mL}$ concentrated $\mathrm{H}_{2} \mathrm{SO}_{4}$ was added before dilution to $500-\mathrm{mL}$ with distilled water.

\section{Iron(II) complexing reagent}

A typical stock solution $(0.005 \mathrm{M})$ of the organic reagents were prepared by dissolving required amount of PDT, PBMPT and PBBT in small volume of ethanol into three different 250-mL volumetric flasks respectively. The solutions were then diluted to required volume with ethanol. Further dilutions of the stock solutions were made for the required concentration of the reagents for spectrophotometric examinations.

\section{Buffer solution}

A buffer solution of $\mathrm{pH} 4.76$ was prepared in a $500-\mathrm{mL}$ volumetric flask by mixing of $250-\mathrm{mL} 2 \mathrm{M} \mathrm{CH} \mathrm{CH}_{3} \mathrm{COOH}$ solution and $250-\mathrm{mL} 2 \mathrm{M} \mathrm{CH}_{3} \mathrm{COONa}$ solution.

\section{Reducing agent}

A $10 \%(w / v)$ solution of pure hydroxylamine hydrochloride was prepared by dissolving $25 \mathrm{~g}$ of the material in $250-\mathrm{mL}$ volumetric flask with distilled water.

\section{Apparatus}

Ultraviolet-visible spectra were recorded in a double beam UV-1800, UV-visible Spectrophotometer, SHIMADZU, Japan. Rectangular glass cells of path length $1 \mathrm{~cm}$ were used throughout this investigation. A digital $\mathrm{pH}$ meter $\mathrm{Mi}$ 151, pH/ORP/Temperature Bench Meter, U.S.A was used for $\mathrm{pH}$ measurements in this research work.

Colour development procedure of iron(II) complexes of organic reagents

The iron(II) complexes of PDT, PBMPT and PBBT were prepared for spectrophotometric examination following general procedure:

5.0-mL of iron(II) solution was pipetted to a $25-\mathrm{mL}$ volumetric flask and $2-\mathrm{mL}$ of $10 \%(\mathrm{w} / \mathrm{v})$ hydroxylamine hydrochloride, 5-mL of the organic reagent solutions, and 5-mL buffer solution of $\mathrm{pH} 4.76$ were added. The contents of the flask were diluted to volume by adding ethanol. Spectra of all solutions were recorded against similarly prepared reagent blanks in the appropriate solvents.

The wavelengths of maximum absorbance, $\left(\lambda_{\max }\right)$ of PDTiron(II) and PBMPT-iron(II) and PBBT-iron(II) complexes were recorded. Specific absorptivity $(a)$ and molar absorptivity $(\varepsilon)$ of different iron(II) complexes at the wavelength of maximum absorbance calculated from the linear regression coefficient in terms of absorbance versus concentration were determined .

Determination of compositions and the conditional formation constants (stability constant) of iron(II) complexes of astriazines

In this study, the stability constant and metal to chelates ratio were determined spectrophotometrically by both mole ratio and Job's continuous variation methods.

\section{Mole ratio method}

In this method, two types of runs were carried out. In the first, the concentrations of organic reagent were varied keeping the iron(II) concentration constant, and in the second, the conditions were reversed.

In the series in which the concentration of the organic reagent was varied, to each of 50-mL volumetric flasks 5.0$\mathrm{mL}$ of standard iron(II) solution (keeping the concentrations of iron(II) constant at $4.475 \times 10^{-5} \mathrm{M}$ and $2.148 \times 10^{-5} \mathrm{M}$ ), 2 -mL of $10 \%$ hydroxylamine hydrochloride solution, $5-\mathrm{mL}$ of buffer solution, followed by a varying amount $(1-28-\mathrm{mL})$ of stock organic reagent solutions $\left(5.0 \times 10^{-4} \mathrm{M}\right)$ were added in turn and then diluted to volume with ethanol. In the second run where the concentration of iron(II) was varied, to each series of $50-\mathrm{mL}$ volumetric flasks were added in turn; 5.0-mL of reagent solutions keeping the 
concentrations of organic reagents constant (at two different values) $2-\mathrm{mL}$ of $10 \%$ hydroxylamine hydrochloride solution, 5-mL of buffer solution, followed by a varying amount (1-30-mL) of stock iron(II) solution $\left(1.79 \times 10^{-4}\right.$ $\mathrm{M})$ and then diluted to volume with ethanol. The absorbances of the different series of solutions were recorded at corresponding wavelengths of maximum absorbance $\left(\lambda_{\max }\right)$. The absorbances were plotted against molar ratio of metal: 1/3 ligand or ligand: metal.

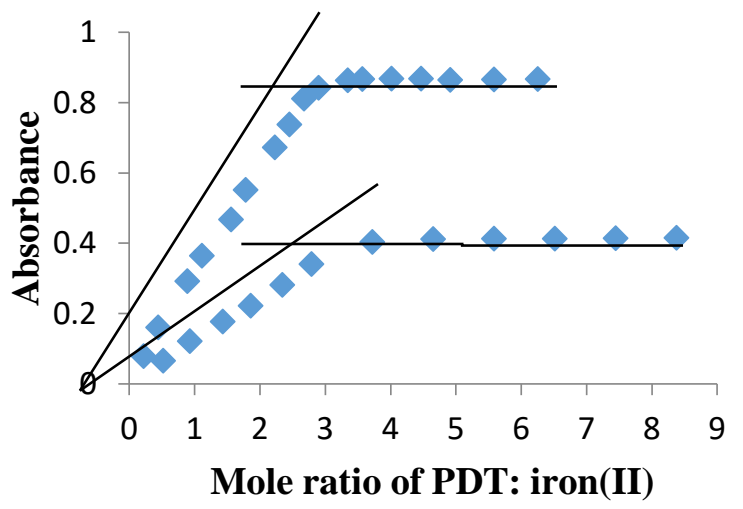

Fig. 1. Variation of PDT concentrations with iron concentration held constant at $4.47 \times 10^{-5} \mathrm{M}$ and $2.14 \times 10^{-5} \mathrm{M}$.

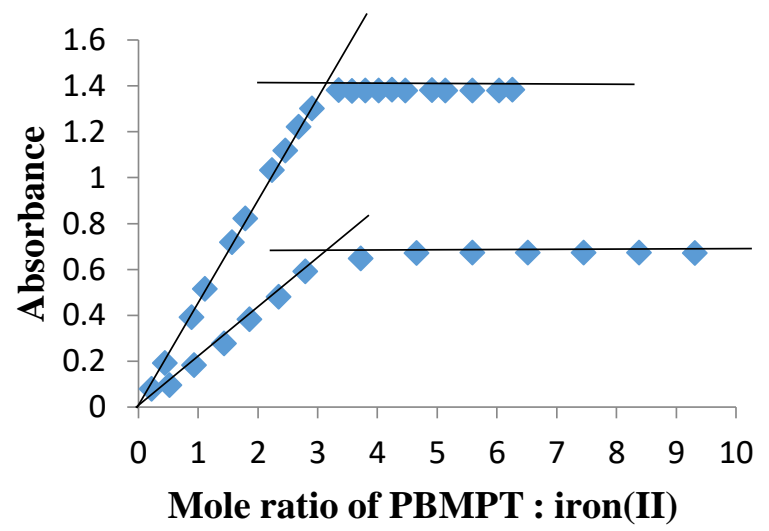

Fig. 2. Variation of PBMPT concentrations with iron concentration held constant at $4.47 \times 10^{-5} \mathrm{M}$ and $2.14 \times 10^{-5} \mathrm{M}$.

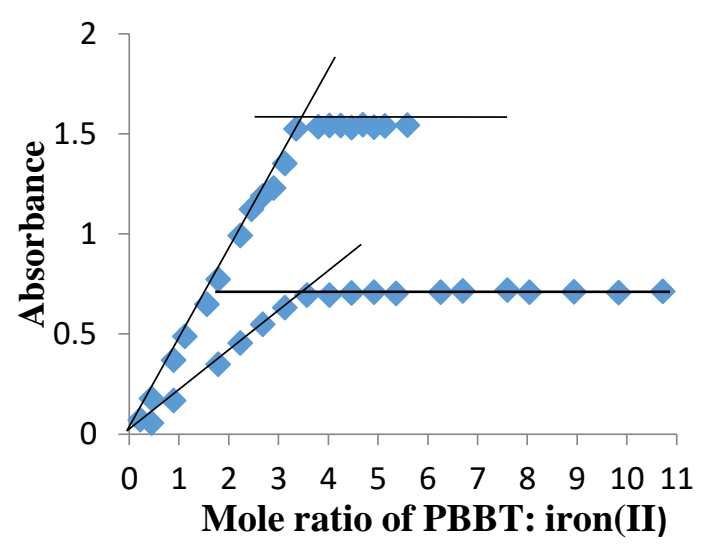

Fig. 3. Variation of PBBT concentrations with iron concentration held constant at $4.475 \times 10^{-5} \mathrm{M}$ and $2.237 \times 10^{-5} \mathrm{M}$.

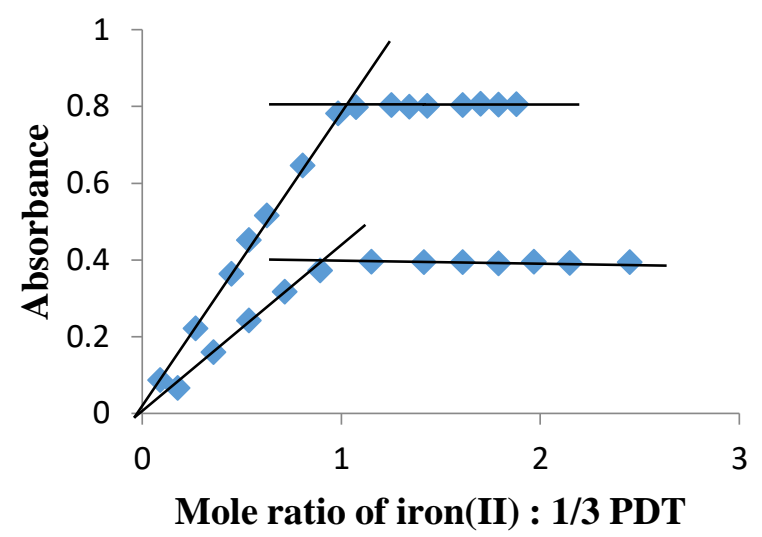

Fig. 4. Variation of iron concentration with PDT concentrations held constant at $1.20 \times 10^{-4} \mathrm{M}$ and $6.0 \times 10^{-5} \mathrm{M}$

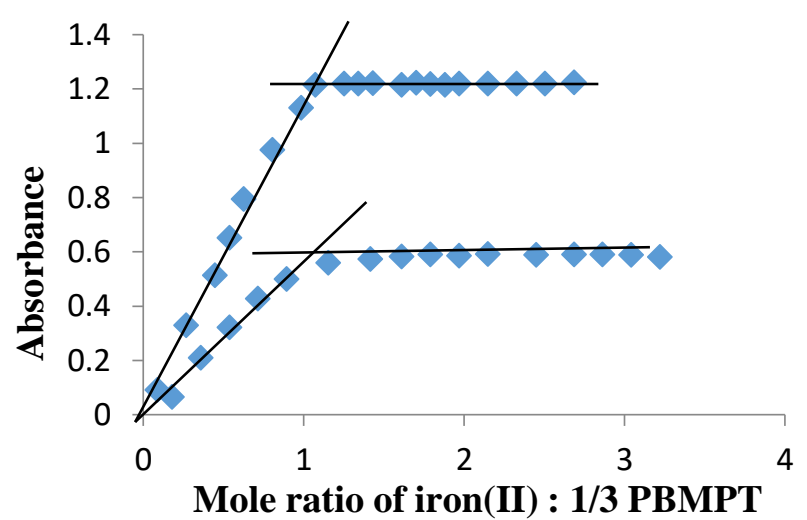

Fig. 5. Variation of iron concentration with PBMPT concentrations held constant at $1.20 \times 10^{-4} \mathrm{M}$ and $6.0 \times 10^{-5} \mathrm{M}$.

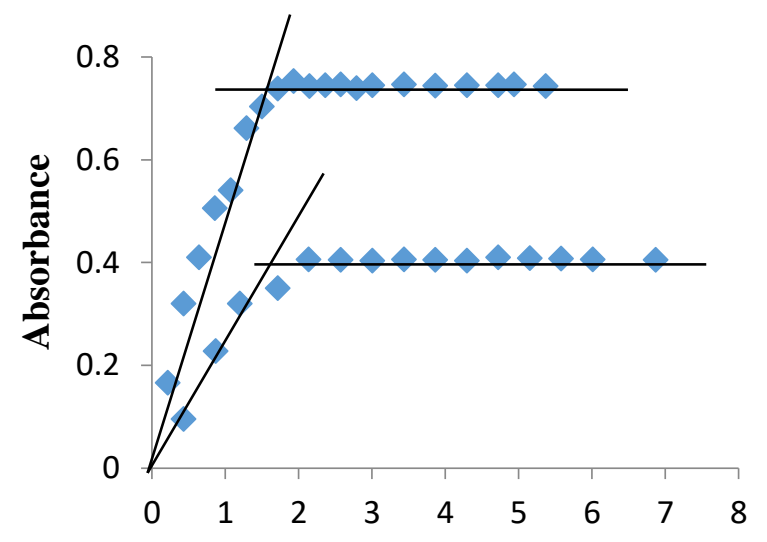

Mole ratio or iron(II) : 1/3 PBBT

Fig. 6. Variation of iron concentration with PBBT concentrations held constant at $5.0 \times 10^{-5} \mathrm{M}$ and $2.5 \times 10^{-5} \mathrm{M}$.

Job's Continuous variations method

This method was carried for the determination of compositions and stability constants of iron(II) complexes of different organic reagents. Various volumes of iron(II) and organic reagents solutions of equal molarity were mixed in a series of 50-mL volumetric flasks maintaining the total concentration at $1.79 \times 10^{-4} \mathrm{M}$. The absorbances of these series of solutions were plotted against the corresponding mole fraction of iron(II). Results of this study are given in Figs. 7-9. 


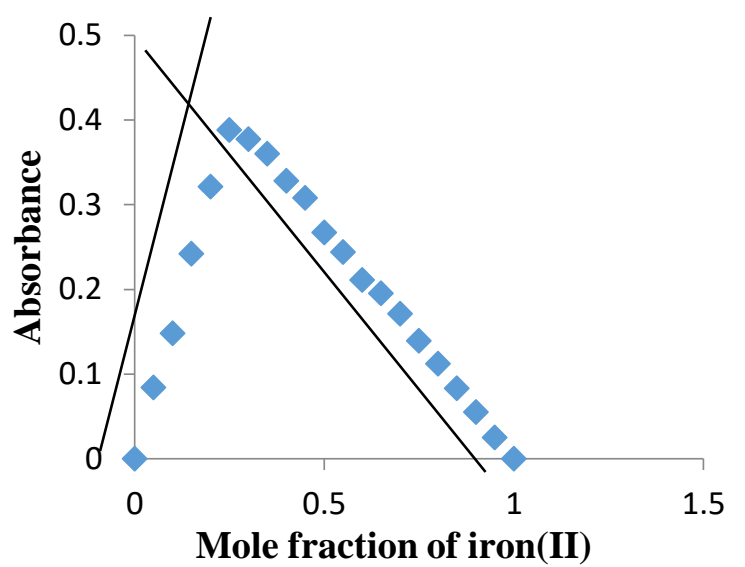

Fig. 7. Continuous variations of PDT and iron(II) concentrations keeping a constant value of $1.79 \times 10^{-4} \mathrm{M}$.

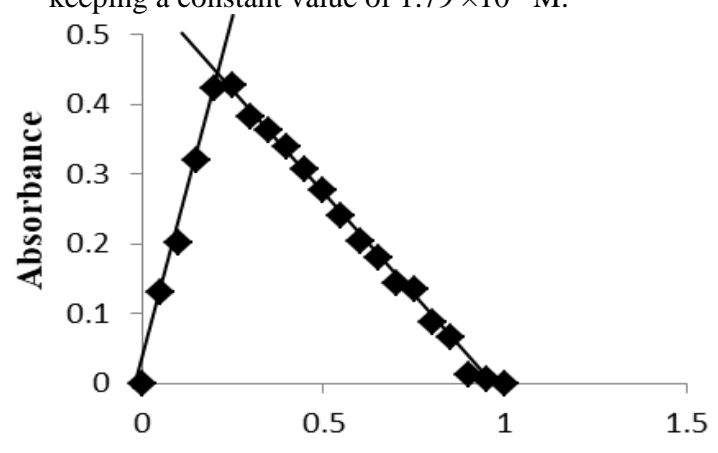

Mole fraction of iron(II)

Fig. 8. Continuous variation of PBBT and iron(II) concentrations keeping constant total concentration of $1.79 \times 10^{-4} \mathrm{M}$.

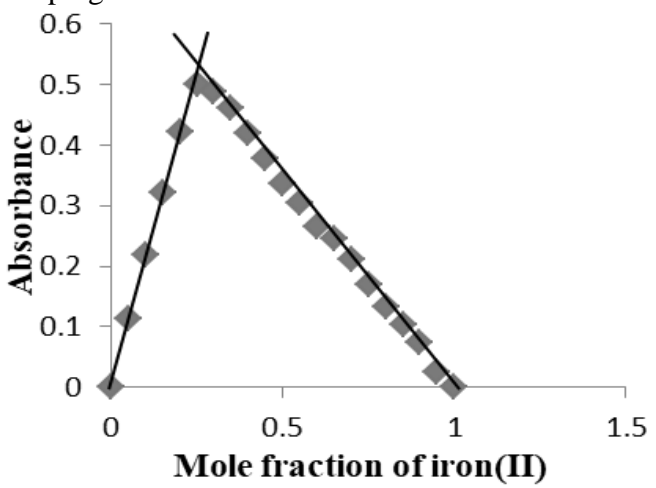

\section{Results and Discussion}

The visible absorption spectrum of the iron(II) complexes of PDT, PBMPT and PBBT showed a single sharp peak with a maximum absorbance at 556, 561 and $566.5 \mathrm{~nm}$ respectively. The molar absorptivities of iron(II) complexes of PDT, PBMPT and PBBT at the wavelength of maximum absorbance in aqueous ethanol medium are 24,126 $\mathrm{Lcm}^{-1} \mathrm{~mol}^{-1}, 31,807 \mathrm{Lcm}^{-1} \mathrm{~mol}^{-1}$ and $31,800 \mathrm{Lcm}^{-1} \mathrm{~mol}^{-1}$ respectively. The spectral characteristics found in this investigation i.e., $\lambda_{\max }$ and molar absorptivity $\left(\epsilon_{\max }\right)$ are almost similar to those of the reported values of Stephen and Islam ${ }^{17}$

The stoichiometry of the iron(II) complexes of as-triazines; PDT, PBMPT and PBBT were determined by both molar ratio and Job's continuous variation methods. The results of this study are given in Figures 1-9. It is clear from these Figures that these ligands PDT, PBMPT and PBBT forming a tris-complex with iron(II) acting as a bidentate ligand.

Since excess regents were required for complete complex formation it was possible to evaluate $K$, the stability constant values of iron(II) complexes by straightforward means. The stability constants values (logK) of iron(II) complexes of PDT, PBMPT and PBBT were calculated following the methods of calculation of $\mathrm{Gibbs}^{15}$ and are summarized in Tables $1-3$ respectively.

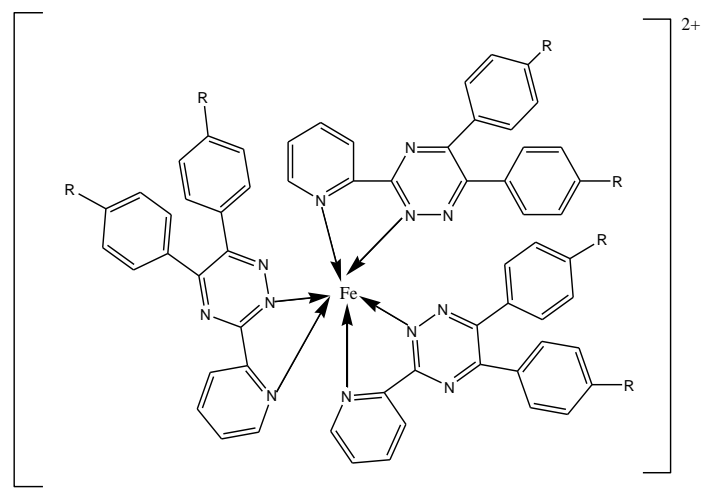

Schematic representation of the complex $\left[\mathrm{FeL}_{3}\right]^{2+}$

Fig. 9. Continuous variations of PBMPT and iron(II) concentrations keeping a constant value of $1.79 \times 10^{-4} \mathrm{M}$.

Table. 1. Stability (conditional formation) constant for the tris(PDT)-iron(II) complex $\left[\mathrm{FeL}_{3}\right]^{2+}$.

\begin{tabular}{|c|c|c|c|c|c|}
\hline Conditions & $\mathrm{Fe}^{2+}: \mathrm{L}$ ratio & $\begin{array}{l}{\left[\mathrm{FeL}_{3}{ }^{2+}\right]^{\mathrm{a}}} \\
(\mathrm{M})\end{array}$ & $\begin{array}{l}{\left[\mathrm{Fe}^{2+}\right]^{\mathrm{b}}} \\
(\mathrm{M})\end{array}$ & $\begin{array}{l}{[\mathrm{L}]^{\mathrm{c}}} \\
(\mathrm{M}) \\
\end{array}$ & $\log _{10} \mathrm{~K}^{\mathrm{d}}$ \\
\hline $\begin{array}{l}{[\mathrm{L}] \text { constant at }} \\
1.2 \times 10^{-4} \mathrm{M},\left[\mathrm{Fe}^{2+}\right] \text { varied }\end{array}$ & $1: 3$ & $3.29 \times 10^{-5}$ & $1.52 \times 10^{-7}$ & $2.13 \times 10^{-5}$ & 16.35 \\
\hline $\begin{array}{l}\text { Continuous variations Both }\left[\mathrm{Fe}^{2+}\right] \text { and } \\
\text { [L] varied }\end{array}$ & $1: 3$ & $1.60 \times 10^{-5}$ & $1.29 \times 10^{-6}$ & $5.70 \times 10^{-6}$ & 16.82 \\
\hline
\end{tabular}


Table. 2. Stability (conditional formation) constant for the tris(PBMPT)-iron(II) complex $\left[\mathrm{FeL}_{3}\right]^{2+}$.

\begin{tabular}{|l|l|l|l|l|l|}
\hline Conditions & $\mathrm{Fe}^{2+}: \mathrm{L}_{\text {ratio }}$ & $\begin{array}{l}{\left[\mathrm{FeL}_{3}{ }^{2+}\right]^{\mathrm{a}}} \\
(\mathrm{M})\end{array}$ & $\begin{array}{l}{\left[\mathrm{Fe}^{2+}\right]^{\mathrm{b}}} \\
(\mathrm{M})\end{array}$ & $\begin{array}{l}{[\mathrm{L}]^{\mathrm{c}}} \\
(\mathrm{M})\end{array}$ & $4.05 \times 10^{-6}$ \\
\hline $\begin{array}{l}{\left[\mathrm{Fe}^{2+}\right] \text { constant at } 4.475 \times 10^{-5} \mathrm{M},[\mathrm{L}]} \\
\text { varied }\end{array}$ & $1: 3$ & $4.34 \times 10^{-5}$ & $1.35 \times 10^{-6}$ & 17.68 \\
\hline $\begin{array}{l}{\left[\mathrm{Fe}^{2+}\right] \text { constant at } 2.148 \times 10^{-5} \mathrm{M},[\mathrm{L}]} \\
\text { varied }\end{array}$ & $1: 3$ & $2.04 \times 10^{-5}$ & $1.04 \times 10^{-6}$ & $3.12 \times 10^{-6}$ & 17.81 \\
\hline $\begin{array}{l}{[\mathrm{L}] \text { constant at } 1.2 \times 10^{-4} \mathrm{M},\left[\mathrm{Fe}^{2+}\right]} \\
\text { varied }\end{array}$ & $1: 3$ & $3.84 \times 10^{-5}$ & $1.64 \times 10^{-6}$ & $4.92 \times 10^{-6}$ & 17.29 \\
\hline $\begin{array}{l}{[\mathrm{L}] \text { constant at } 6.0 \times 10^{-5} \mathrm{M},\left[\mathrm{Fe}^{2+}\right]} \\
\text { varied }\end{array}$ & $1: 3$ & $1.85 \times 10^{-5}$ & $1.50 \times 10^{-6}$ & $4.50 \times 10^{-6}$ & 17.13 \\
\hline $\begin{array}{l}\text { Continuous variations } \\
\text { Both }\left[\mathrm{Fe}^{2+}\right] \text { and }[\mathrm{L}] \text { varied }\end{array}$ & $1.67 \times 10^{-5}$ & $1.20 \times 10^{-6}$ & $3.60 \times 10^{-6}$ & 17.47 \\
\hline
\end{tabular}

Table. 3. Stability (conditional formation) constant for the tris(PBBT)-iron(II) complex, $\left[\mathrm{FeL}_{3}\right]^{2+}$.

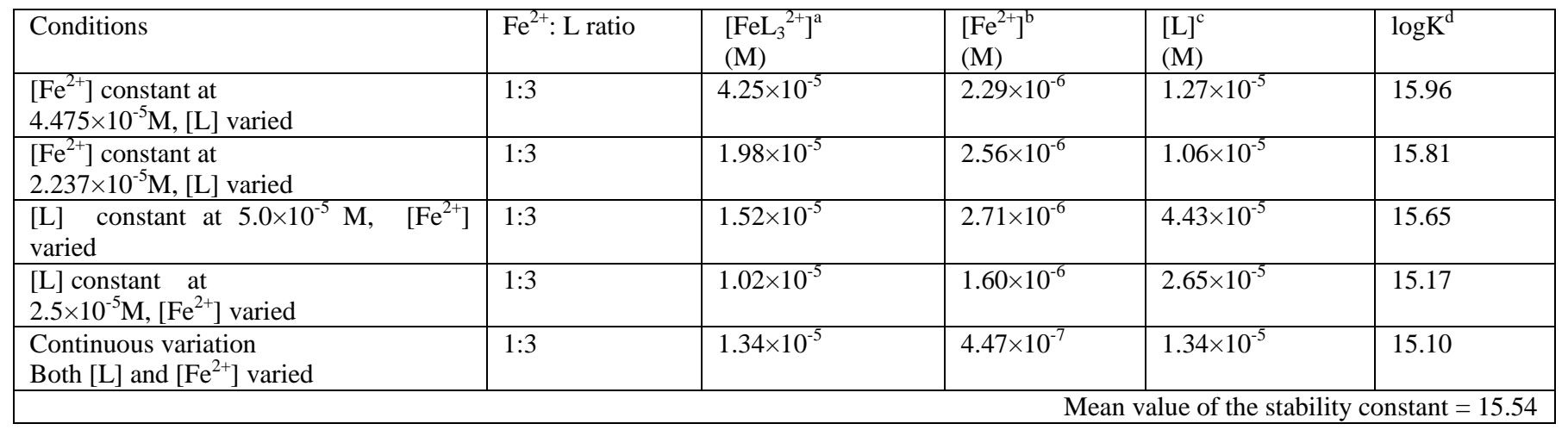

A typical calculation is given below:

$\mathrm{Fe}^{2+}+3 \mathrm{~L} \rightarrow \mathrm{FeL}_{3}^{2+}$

${ }^{\mathrm{a} C}$ Calculated using $\epsilon_{\max }$,

$\left[\mathrm{Fe}^{2+}\right]^{\mathrm{b}}=\left[\mathrm{Fe}^{2+}\right]_{\text {initial }}-\left[\mathrm{FeL}_{3}{ }^{2+}\right]^{\mathrm{a}}$,

$[\mathrm{L}]^{\mathrm{c}}=[\mathrm{L}]_{\text {initial }}-3\left[\mathrm{FeL}_{3}{ }^{2+}\right]^{\mathrm{a}}$

$\mathrm{K}^{\mathrm{d}}=\left[\mathrm{FeL}_{3}{ }^{2+}\right]^{\mathrm{a}} /\left[\mathrm{Fe}^{2+}\right]^{\mathrm{b}}[\mathrm{L}]^{\mathrm{c} 3}$

The mean $\log \mathrm{K}$ values obtained for iron(II) complexes of PDT, PBMPT and PBBT were 16.48, 17.48 and 15.54 respectively. These values are very high reflecting the formation of very stable complexes. These are well comparable with the reported values for the iron(II) complexes of 2,2'-bipyridine, (16.4-17.6) and 1,10phenanthroline $(20.2-21.5)^{6,7}$, Ferrozine-15.6 ${ }^{15}$ and Ferene-14.9 ${ }^{16}$. Ferrozine is widely used for the spectrophotometric determination of iron. Easier way of synthesis of PBMPT from commercially available relatively cheaper reactants, higher sensitivity and stability constant values reflects that it would be a better reagent for iron determination.

\section{References}

1. Welcher. F. J, 1947. Organic Analytical Reagents, Van Nostrand Co., New York, 4, 48.

2. Feigl. F, 1923. Spot tests and colour reactions as methods of microchemical work. Mikrochemie. 1, 4.
3. Hutton A. T. and P. W. Linder, 2006. Stability constants and their determination, Encyclopedia of Inorganic Chemistry, John Wiley \& Sons, Ltd.

4. Perrin. D. D and B. Dempsey, 1974. Buffer for pH and metalion control, 3rd Ed. 109-111.

5. Krumholz. P, 1953. Studies on the coordinate bond. II. ferrous complexes of $\alpha$-diimines. J. Am. Chem. Soc., 75, 2163-2166.

6. Sillen. L. G. and A. E. Martell, 1964. Stability constants of metal ion complexes, $2^{\text {nd }}$ ed. The Chemical Society, London.

7. Sillen. L. G and A. E. Martell, 1971. Stability constants of metal ion complexes Supplement No. 1, The Chemical Society, London .

8. Case. F. H, 1965. The preparation of hydrazidines and astriazines related to substituted 2-cyanopyridines. J. Org. Chem., 30, 931.

9. Case. F. H, 1959. The synthesis of certain substituted 1, 3, 5triazines containing the ferroin group. J. Org. Chem., 81, 905.

10. Case. F. H, 1968. The preparation of certain new diphenyl and bis(2-pyridyl) as-triazines J. Heterocycl. Chem., 5, 223,413 and 431 .

11. Case. F. H and A. A. Schilt, 1980. Synthesis of certain pyridinyl and diazinyl hydrazones containing one or more ferroin groups and their chromogenic reactions with iron, copper, cobalt and nickel. Talanta., 26, 85-89. 
12. Schilt. A. A, 1969. Analytical Applications of 1,10Phenanthroline and Related Compounds. Vol. 32 Pergamon press, New York.

13. Schilt. A. A, 1966. Some new chromogens for iron, cobalt, and copper substituted hydrazidines and 1,2,4-triazines containing the ferroin group, Talanta, 13, 895-902.

14. Stookey. L. L, 1970. . Ferrozine-a new spectrophotometric reagent for iron. Anal. Chem. 42, 779.

15. Gibbs. C. R, 1976. Characterization and application of Ferrozine iron reagent as a ferrous iron indicator. Anal. Chem. 48, 1197.

16. Hennessy. D. J. and G. R. Reid, F. E. Smith and S. I., Thomson. 1984. Ferene-a new spectrophotometric reagent for iron. Can. J. Chem.,62, 721-724.
17. Islam. M. A. and W. I Stephen, 1993. 3,5,6-Trisubstituted 1,2,4-triazines as analytical reagents Part I. Compounds containing the ferroin functional group or iron(II)-methine chromophore. Anal. Chem. Acta, 274, 335-346.

18. Islam M. A., S. Begum, M. Parvin and M. M. Hossain, 2019. Determination of Trace Amount of Iron with as-Triazine Containing Ferroin-Functional Group. Dhaka Univ. J. Sci, 67(2), 335-346.

19. Furniss. B. S, A. J. Hannaford, P. W. G. Smith and A. R. Tatchell, 1978. Vogel's text book of practical organic chemistry, $4^{\text {th }}$ Ed. 1043-1046. 